\title{
SYNTHESIS AND LIPOOXIGENASE INHIBITION OF COUMARIN DERIVATIVES
}

\section{Melita Lončarić1 ${ }^{,}$Valentina Pavić ${ }^{2}$ Maja Molnar ${ }^{1}$ \\ ${ }_{1}^{1}$ Josip Juraj Strossmayer University of Osijek, Faculty of Food Technology Osijek \\ ${ }^{2}$ Department of Biology, Josip Juraj Strossmayer University of Osijek}

\section{INTRODUCTION}

\begin{abstract}
Coumarin derivatives are an important group of biologically active compounds that have found a wide range of applications in pharmacy and medicine. For this reason, their extraction from plants, as well as the synthesis in laboratories have been increased lately. Many studies have been conducted and various coumarins have shown different biological activities such as antibacterial, antifungal, anti-inflammatory, anticoagulant, antioxidant, anticancer, anti-HIV and much more. Coumarins can also act as enzyme inhibitors. It has been proven that coumarins inhibit many enzymes, including lipoxygenases. Lipoxygenases (LOX) (Figure 1.) are iron-containing enzymes that convert polyunsaturated fatty acids into biologically active compounds involved in the inflammatory and immune responses. Sometimes, it is necessary to inhibit those enzymes to avoid adverse reactions in plants and animals as well as in humans. During compounds synthesis in laboratory, it is important to minimize environmental contamination. Therefore, use of deep eutectic solvents is preferable, due to their desirable properties (low toxicity, high availability, low inflammability, high recyclability, low volatility and low price).
\end{abstract}

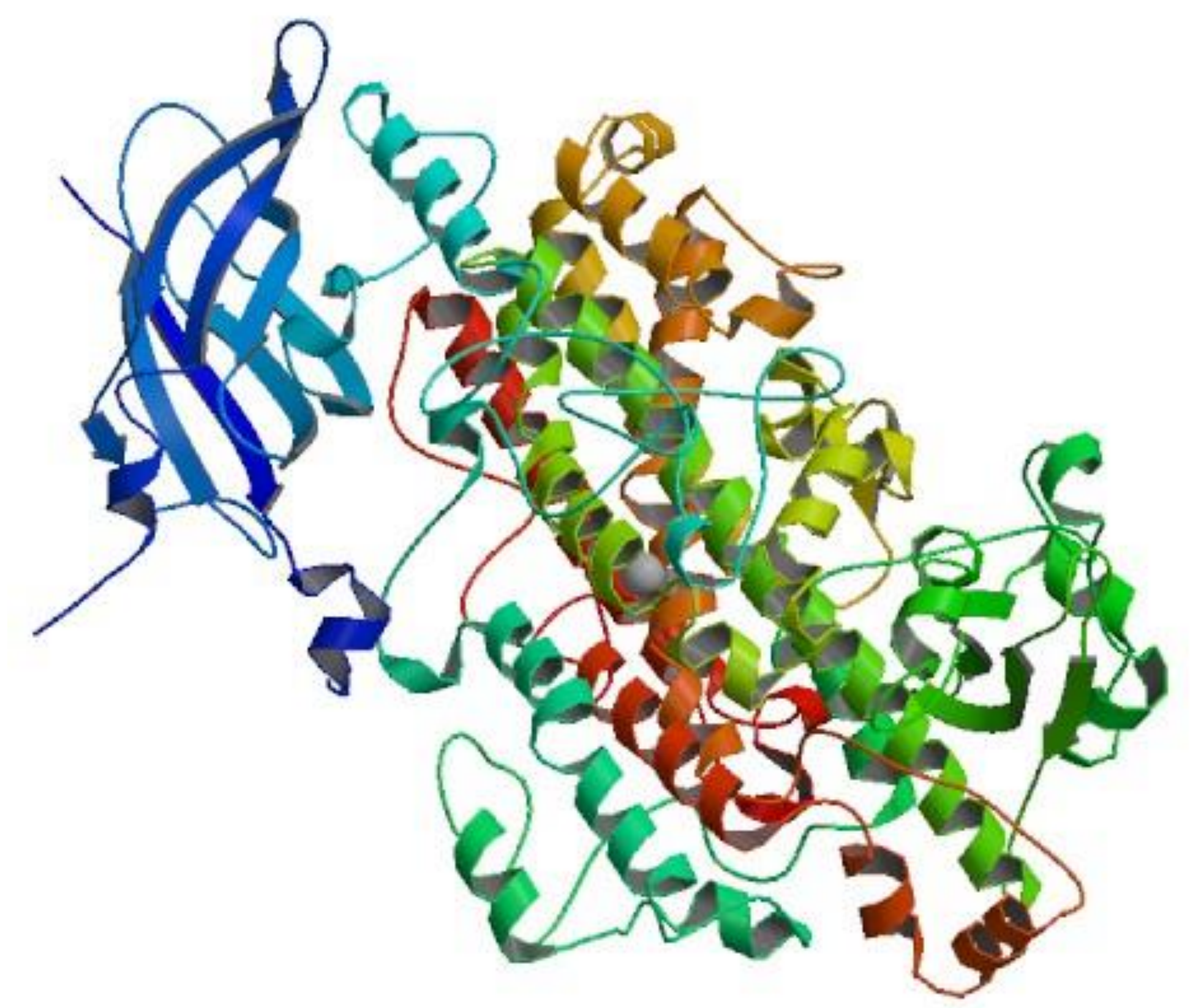

Figure 1. Structure of soybean lipoxygenase

\section{MATERIALS AND METHODS}

\section{Procedure for synthesis of coumarin derivatives}

Coumarin derivatives were synthesized via Knoevenagel condensation as is shown in Scheme 1. Model reaction of salicylaldehyde and dimethyl malonate into coumarin was performed in 20 different DESs as a reaction media in order to find the best DES, which was proven to be choline chloride:urea (ChCl:U 1:2). Mixtures were stirred until full consumption of reactants, monitored by: TLC. Upon completion of reaction, water was added and precipitated product filtered. Obtained: crystals are weighed and melting points of crystals were determined.

\section{Soybean lipoxygenase inhibition}

Lipoxygenase activity was determined with linoleic acid sodium salt as substrate. Lipoxygenase activity was measured in the presence of coumarin derivatives (Scheme 1). Compounds were dissolved in DMSO at $10 \mathrm{mM}$ concentration and added $(10 \mu \mathrm{L})$ to the reaction mixture containing $840 \mu \mathrm{L}$ of borate buffer $(0.2 \mathrm{M}, \mathrm{pH}=9), 100 \mu \mathrm{L}$ aqueous solution of lipoxygenase $(1500 \mathrm{U} / \mathrm{mL})$ and $50 \mu \mathrm{L}$ aqueous solution of linoleic acid sodium salt $(2 \mathrm{mM})$. Increase in the absorbance at $234 \mathrm{~nm}$ was measured using spectrophotometer Specord 200 (Germany).

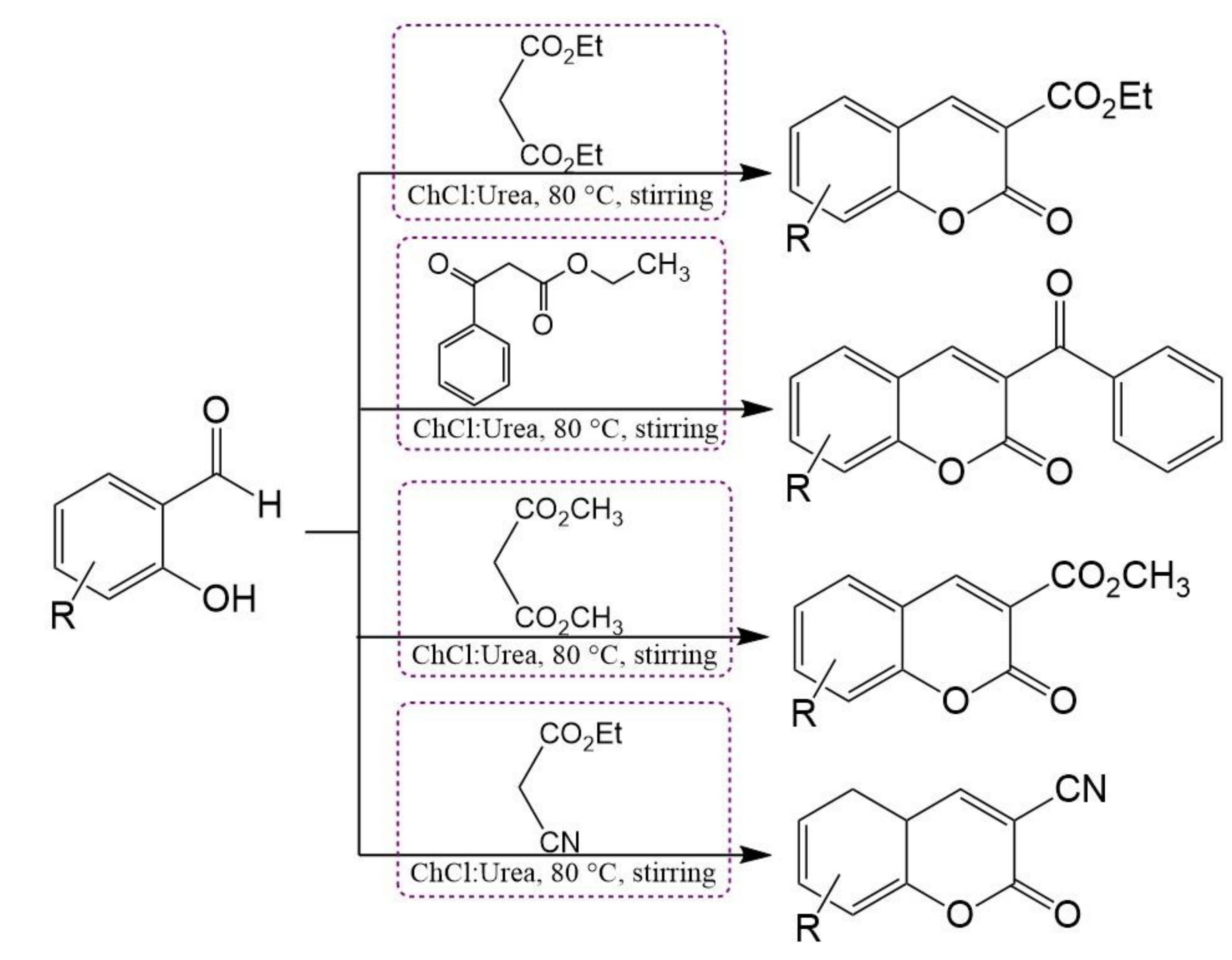

Scheme 1. Synthesis of coumarin derivatives via Knoevenagel condensation

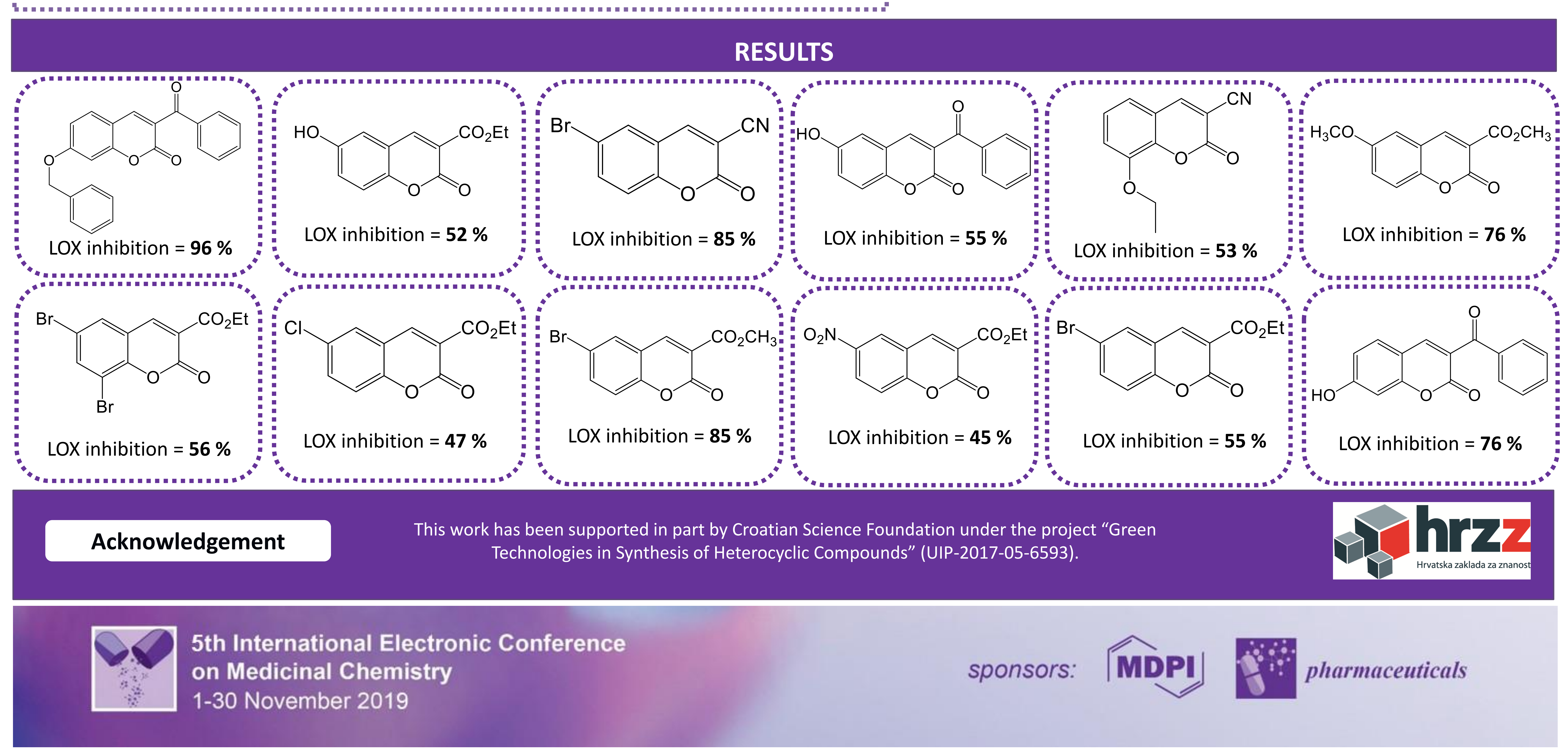

